\title{
Comparison of Salivary Acid Phosphatase Levels in Pregnant Women with Stress and without Stress in Ahvaz, Iran
}

\section{ISSN: 2640-9666}

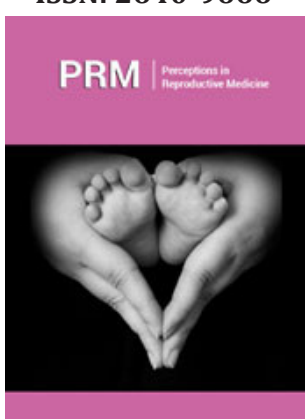

*Corresponding author: Sareh Aberoumand, Infertility and Perinatology Research Center, Iran

Submission: 漈July 23, 2021

Published: 海 September 03, 2021

Volume 4 - Issue 5

How to cite this article: Aberoumand M, Mojgan Barati, Salimeh Chegini N, Sareh Aberoumand, Hadi Kajbafnejad. Comparison of Salivary Acid Phosphatase Levels in Pregnant Women with Stress and without Stress in Ahvaz, Iran. Perceptions Reprod Med. 4(5). PRM. 000596. 2021. DOI: 10.31031/PRM.2021.04.000596

Copyright@ Sareh Aberoumand, This article is distributed under the terms of the Creative Commons Attribution 4.0 International License, which permits unrestricted use and redistribution provided that the original author and source are credited.

\author{
Aberoumand $\mathbf{M}^{1}$, Mojgan Barati ${ }^{2}$, Salimeh Chegini ${ }^{3}$, Sareh Aberoumand ${ }^{2 *}$ and \\ Hadi Kajbafnejad ${ }^{4}$ \\ ${ }^{1}$ Department of Clinical Biochemistry, Faculty of Medicine, Iran \\ ${ }^{2}$ Infertility and Perinatology Research Center, Iran \\ ${ }^{3}$ Department of Midwifery, Faculty of Nursing \& Midwifery, Iran \\ ${ }^{4}$ Department of Psychology, Iran
}

\begin{abstract}
Background: Acid Phosphatase (ACP) is an enzyme used as a non-invasive biomarker to study the activity of the lysosomal sympathetic system. The aim of this study was to compare the levels of salivary ACP in stressed and non-stressed pregnant women in Ahvaz, Iran.
\end{abstract}

Study design: A causal-comparative study.

Methods: This was a causal-comparative study using purposive sampling technique. The subjects were randomly selected. The instruments used in this study were the Orly \& Girdano stress and demographic questionnaires. Saliva samples were collected from 50 pregnant women with stress and 50 pregnant women without stress. Salivary ACP was determined and compared using paired independent sample $t$ test.

Results: Overall, the findings of the present study showed that the differences mean of salivary ACP levels in the stressed pregnant women was significantly higher than pregnant women without stress $(\mathrm{P}<0.05)$.

Conclusion: We found differences in pregnant women with stress and without stress regarding to salivary ACP levels. The results of this study showed that stress causes an increase in salivary ACP secretion.

Keywords: Acid phosphatase; Saliva; Enzyme; Stress; Pregnant women; Biomarker

\section{Introduction}

During pregnancy some women experience daily stress. These stresses include depression, anxiety, anger, day-to-day challenges, sudden change of environment, social isolation, and pathological conditions [1-3]. Psychological stress in women during pregnancy, childbirth and breastfeeding has been found to decrease the gestation period, which results in low birth weight [4] and can have another unfortunate consequence, including miscarriage, nausea and vomiting, preeclampsia, and postpartum depression. Also, it may inhibit the immune system, increase the risk of infectious wounds and neonatal infections. The typical somatic response to these and other similar stressors is elevation of cortisol hormone. Cortisol is known to cross the placenta and consequently influence various aspects of development in the human fetus [2]. The effects of elevated cortisol levels on the fetus may vary from defective development [5] to spontaneous abortion [6].

Biochemical research has shown that biochemical metabolites, including the hormones cortisol catecholamines (such as epinephrine and norepinephrine) and Neuro-endocrine markers, are reliable biological markers for biological stress system responses [7]. Plasma measurements of epinephrine and norepinephrine are used to evaluate the SympatheticAdrenal-Medullary (SAM) system. However, because many enzymes may be degraded in 
this method due to the preparation of serum or plasma, protein (enzyme) salivary acid phosphatase can be used as an indicator of SAM activity. Also, laboratory analysis of saliva has become an important technique for the assessment of physiological and pathological conditions, mostly due to the origin, composition, and functions of saliva, as well as its interactions with other body systems and structures. Other favorable aspects of saliva testing include painless sampling, ease of storage, and low cost of analysis as compared with blood $[7,8]$.

New research in biomedical and psychological research shows that salivary Acid Phosphatase (ACP) is salivary bio sensitive to stress-related changes in the body and can reflect the activity of the sympathetic nervous system. Simultaneous increase in plasma acid phosphatase and catecholamine activity with physical and psychological stressors has led to the hypothesis that acid phosphatase can be a non-invasive alternative measure for catecholamines. As mentioned, the stress can increase enzymatic and hormonal activity. Therefore, this study is designed to answer the question whether there is a difference between salivary ACP activity in stressed and non-stressed pregnant women in Ahvaz, Iran?

\section{Methods}

In this causal-comparative study, 50 pregnant women with stress and 50 pregnant women without stress were compared. The population under study included all pregnant women who referred to gynecology and obstetrics clinic of Imam Khomeini hospital in Ahvaz, Iran in 2020. The research sample included 100 pregnant women who were selected through simple random sampling method from among the population according to the sample size and based on inclusion and exclusion criteria. The instruments used to collect the data were demographic and Orly \& Giordano Stress Questionnaires. The method of data collection in this study was that after coordination with gynecologists and stating the purpose of the study, the subjects were asked to fill in the questionnaire. In the next step, their saliva samples are collected in passive tubes for five minutes.

Orly \& Giordano Stress Questionnaire was created in 1980. This questionnaire is composed of 14 items and 4 subscales of haste (6 questions), competitive (4 questions), greed ( 2 questions) and unplanned work (2 questions), which is used for self-assessment of personality according to use for type A and B character patterns.
The answer to this questionnaire is based on a scale (almost always true of me $=a$, usually true of me $=b$, rarely true of me $=c$, never true of me=d). Since this questionnaire was standard, it possessed a good level of validity. Besides, the reliability of this scale based on Cronbach's alpha coefficients was obtained by Costa and McCray for the $\mathrm{N}, \mathrm{E}, \mathrm{O}, \mathrm{A}$, and $\mathrm{C}$ properties of $0.66,0.77,0.73,0.68$, and 0.81 , respectively. In the present study, the reliability coefficients of the questionnaire using Cronbach's alpha for neuroticism (0.76), go-orientation (0.58), openness to experience (0.77), agreeability (0.72), and conscientiousness (0.81) was calculated.

Simultaneously with filling in the questionnaire, saliva sample was taken to measure the ACP enzyme under the same conditions. For saliva sampling, the research samples were asked to collect their saliva for five minutes in designated tubes by passive method. Saliva samples in two stages were immediately sent to the biochemistry laboratory for analysis by spectrophotometric test, under cold conditions (carrying a tube containing saliva near ice). All samplings were performed in the morning at 9-12 o'clock. Inclusion criteria included lack of infectious disease, autoimmunity, inherited immunodeficiency, mental illness, no immunosuppressive drugs, no vaccine or blood transfusions, no smoking, and no surgery during the two months prior to Sampling was salivary.

\section{Statistical analysis}

In the present study, two methods of descriptive and inferential statistics were used to analyze the research data. In order to describe the current situation, (frequency, frequency percentage, average, standard deviation, minimum and maximum scores) have been used. The normality of data distribution was evaluated using Kolmogorov-Smirnov test (K S). To analyze the information and data obtained in the hypotheses (independent t-test and multivariate analysis of variance) in the form of 21 SPSS software was used and all research hypotheses were tested at the significance level of 0.05 $(\mathrm{P}<0.05)$.

\section{Result}

The characteristics of the participants for this study including age, educational status, job and parity have been presented in Table 1. There was a significant difference between salivary acid phosphatase activity in stressed and non-stressed pregnant women $(\mathrm{P}<0.05)$ (Table 2). The mean (SD) of Orly \& Girdano stress questionnaire scores in stressed pregnant women was 8.4 (2.1) and in non-stressed pregnant women was 2.9 (0.9) (Table 3).

Table 1: Sample characteristics of participants $(N=100)$.

\begin{tabular}{|c|c|c|c|c|c|}
\hline \multirow{2}{*}{\multicolumn{2}{|c|}{ Characteristics }} & \multicolumn{2}{|c|}{ Stressed Pregnant } & \multicolumn{2}{|c|}{ Non-Stressed Pregnant } \\
\hline & & \multirow{2}{*}{$\frac{\text { Num }}{8}$} & \multirow{2}{*}{$\begin{array}{c}\text { Percent } \\
16\end{array}$} & \multirow{2}{*}{$\frac{\text { Num }}{7}$} & \multirow{2}{*}{$\begin{array}{c}\text { Percent } \\
14\end{array}$} \\
\hline \multirow{4}{*}{ Age (in years) } & $18-20$ & & & & \\
\hline & $20-22$ & 15 & 30 & 16 & 32 \\
\hline & $22-24$ & 20 & 40 & 21 & 42 \\
\hline & $>24$ & 7 & 14 & 6 & 12 \\
\hline \multirow{2}{*}{ Educational status } & Bachelor's degree & 15 & 30 & 13 & 26 \\
\hline & master's degree & 35 & 70 & 37 & 74 \\
\hline
\end{tabular}




\begin{tabular}{|c|c|c|c|c|c|}
\hline \multirow{2}{*}{ Job status } & Employed & 45 & 90 & 43 & 7 \\
\cline { 2 - 6 } & Non-employed & 5 & 10 & 29 & 14 \\
\hline \multirow{2}{*}{$\begin{array}{c}\text { Number of } \\
\text { pregnancies }\end{array}$} & First pregnancy & 36 & 72 & 21 & 58 \\
\cline { 2 - 6 } & Second pregnancy & 14 & 28 & 42 \\
\hline
\end{tabular}

Table 2: Descriptive index of ACP activity in two groups of pregnant women with stress and without stress.

\begin{tabular}{|c|c|c|c|}
\hline Descriptive Variables & Stressed Pregnant & Non-Stressed Pregnant & P* \\
\hline Mean (SD) & $1.5(6.7)$ & $0.0004(0.00048)$ & 0.001 \\
\hline
\end{tabular}

*Independent Two Sample Mean Test

Table 3: Descriptive variables of Orly \& Girdano stress questionnaire scores in two groups of stressed and non-stressed pregnant women.

\begin{tabular}{|c|c|c|}
\hline Descriptive Variables & Stressed Pregnant & Non-Stressed Pregnant \\
\hline Mean (SD) & $8.4(2.1)$ & $2.9(0.9)$ \\
\hline Minimum & 4 & 1 \\
\hline Maximum & 13 & 4 \\
\hline
\end{tabular}

\section{Discussion}

Stress is an adaptive response to environmental challenges, but stressors during pregnancy may have a negative effect on the health of pregnant women and their infants [9]. During pregnancy and childbirth, dramatic changes have occurred in women's moods that make them very sensitive to psychological stimuli and sometimes cause psychological problems in them. Therefore, in this period, the possibility of developing conditions such as psychosis, depression, anxiety, morbid fear and obsessive-compulsive disorder is high [10]. The two indicators of mental health and social support during pregnancy are likely to have significant effects on fetal development, pregnancy outcomes, birth weight and birth time. Due to the lack of reporting such a study in Iran, the present study was performed with the purpose of comparing the activity of salivary acid phosphatase and beta pregnant women with stress and without stress in Ahvaz, Iran.

The results of this study showed that the mean activity of salivary acid phosphatase enzyme in pregnant women with stress is higher than pregnant women without stress. So far, no study has been conducted with the aim of our study that can compare the results. However, several studies have measured the levels of other stress hormones in pregnant women as well as during childbirth, some of which confirm the results of our study, which we will mention below.

In the study of Pluess et al. [11], maternal anxiety at the beginning and end of pregnancy was significantly associated with salivary cortisol levels in pregnant women. Also, in the study by Mirzaei et al. [12], significant relationship between cortisol concentration plasma and anxiety levels were observed during labor, these findings are consistent with the results of our study. but in the study by Harville et al. [13] there was not a significant relationship between perceived anxiety and stress in pregnancy. Also, Rando et al. [14] reported that there was not a significant relationship between salivary cortisol levels and overt anxiety in pregnant women at 35 weeks of gestational age. Gerald et al. [15] reported thar for each $1.0 \%$ increase in negative mood there was a corresponding $1.9 \%$ increase in cortisol. This association was unaffected by advancing gestational age. Researchers suggest that cortisol is a plausible biological mechanism for transducing the effects of maternal psychological distress during pregnancy to fetal development. Explaining the findings of the study, it can be said that $\mathrm{CRH}$ is secreted from the placenta into the mother's blood during pregnancy and plasma cortisol levels increase. This can increase emotional distress such as anxiety and depression in pregnant women. On the other hand, as mentioned, in pregnancy the hypothalamic pituitary gland adrenal is underworked to protect the pregnant women's brain against the severe hormonal changes that occur during this period. This can also increase anxiety and depression during pregnancy and postpartum.

\section{Conclusion}

In conclusion, we found differences in pregnant women with stress and without stress regarding to salivary acid phosphatase levels. The results of this study are used as a guide for planners of pregnancy care clinics and infertility treatment centers to increase the importance of recognizing issues related to fear, frustration, stress and recognizing stressed pregnant women in the content of educational strategies. It is recommended that serum acid phosphatase levels be examined for future studies.

\section{Ethical issues}

The study was approved scientifically by research committee of Islamic Azad University Behabahan branch and ethically by the ethic committee of the university.

\section{References}

1. Lazinski MJ, Shea AK, Steiner M (2008) Effects of maternal prenatal stress on offspring development: A commentary. Arch Womens Ment Health 11(5-6): 363-375.

2. Field T, Diego M (2008) Cortisol: The culprit prenatal stress variable. Int J Neurosci 118(8): 1181. 
3. Talge NM, Neal C, Glover V (2007) Antenatal maternal stress and longterm effects on child neurodevelopment: How and why? J Child Psychol Psychiatry 48(3-4): 245-261.

4. Wadhwa PD (2005) Psychoneuroendocrine processes in human pregnancy influence fetal development and health Psychoneuroendocrinology 30(8): 724-743.

5. Obel C, Hedegaard M, Henriksen TB, Secher NJ, Olsen J, et al. (2005) Stress and salivary cortisol during pregnancy. Psychoneuroendocrinology 30(7): 647-656.

6. Nepomnaschy PA, Welch KB, McConnell DS, Bobbi S Low, Strassmann BI, et al. (2006) Cortisol levels and very early pregnancy loss in humans. Proc Natl Acad Sci USA 103: 3938-3942.

7. Lupien SJ, Fiocco A, Wan N, Maheu F, Lord C, et al. (2005) Stress hormone and human memory function across the lifespan. Pcychoneroendocrinology 30(3): 225-242.

8. Al Kawas S, Rahim ZH, Ferguson DB (2012) Potential uses of human salivary protein and peptide analysis in the diagnosis of disease. Arch Oral Biol 57(1): 1-9.

9. Benjamin J, Sodack M (2010) Comperhensive textbook of psychiatry. ( $8^{\text {th }}$ edn), Lippincott, New York, USA.
10. Jannati I, Khaki N (2005) Psychology midwifery. Jameenegar, Tehran, Iran, pp. 1468-147.

11. Pluess M, Bolten M, Pirke KM, Hellhammer D (2010) Maternal trait anxiety, emotional distress, and salivary cortisol in pregnancy. Biol Psychol 83 (3): 169-175.

12. Mirzaie F, Keshtgar S, Kaviani M, Rajaiefard A (2009) The effect of lavender essence smelling during labor on cortisol and serotonin plasma levels and anxiety reduction in nulliparous women. J Kerman Univ Med Sci 16(3): 245-254.

13. Harville EW, Savitz DA, Dole N, Herring AH, Thorp JM (2009) Stress questionnaires and stress biomarkers during pregnancy. J Womens Health (Larchmt) 18(9): 1425-1433.

14. Rondó PH, Vaz AJ, Moraes F, Tomkins A (2004) The relationship between salivary cortisol concentrations and anxiety in adolescent and nonadolescent pregnant women. Braz J Med Res 37(9): 1403-1499.

15. Gerald F, Giesbrecht, Campbell T, Letourneau N, Kooistra L, et al. (2012) Psychological distress and salivary cortisol covary within persons during pregnancy. Psychoneuroendocrinology 37(2): 270-279.

For possible submissions Click below: 